\title{
Strengths-based Assessments and Recovery in Mental Health: Reflections from Practice
}

\author{
Abraham Francis \\ James Cook University, Australia \\ *Corresponding Author: abraham.francis@jcu.edu.au
}

\begin{abstract}
Social workers in the mental health sector are required to undertake assessments to determine the needs of their clients and to use appropriate strategies of interventions in a very demanding and compelling environment. One of the critical questions being asked in this context is- What do social workers really do in an assessment? And how do they do the assessment? Is a strengths based assessment model feasible in a predominantly biomedical model of practice? What is recovery? How can these concepts be applied in practice? How can the invisible nature of social work intervention be made more explicit and thus develop a sense of professional leadership? These are some of the questions that prompted this paper. Hence, in this paper the author discusses the relevance of strengths based philosophy and addresses how these ideas can be employed in adopting strengths- based assessment practice, and a recovery practice frame work in the mental health field with a special focus on social work. This is further illustrated with two case studies, which helps the readers to form questions and provides some practice tips for social workers to become an effective recovery oriented practitioner in the field.
\end{abstract}

Keywords Mental Health, Strength-based Assessment, Recovery

\section{Introduction}

Mental health problems are very common these days. Mental health is a state of emotional and social wellbeing in which the individual can cope with the normal stresses of life and achieve his or her potential. It includes being able to work productively and contribute to community life. A mental illness is a "clinically diagnosable disorder that significantly interferes with an individual's cognitive, emotional or social abilities" (Australian Health Ministers, 2003) The individuals affected by mental illness have very legitimate health care rights and needs and social workers support these people on their journey towards recovery (Francis, 2012).

Social workers are trained to use ICD 10 and DSM 5 in their practice. While they are required to use these, it is also important to look at it critically with the value base of the profession and to examine whether it marginalises people in accessing services. It is within this context, that strengths based assessment has gained some momentum among practitioners. They view that assessments are important as they provide clients with appropriate referrals and offer treatment options. This diagnostic/assessment language too is important for social workers to establish a meaningful and purposeful relationship and communication with the multidisciplinary team members in the best interest of clients. However, what matters in a strengths based assessment is that it sees to ask questions towards strengths that help the client to reframe their issues/thinking, and explores exception finding aspects in their life which is a quite unique way of listening to the lived experience of clients as they are experts by their experience.

"Recovery oriented approach", "recovery movement", "recovery oriented practices" are found to be very common terms used interchangeably in the field of mental health practice in recent times and especially in western countries. Social workers have embraced this shift in practice with a great sense of commitment and passion, though there is still debate about the leadership in this area of practice. (Hyde, Bowles, \& Pawar, 2014, p. 5). Recovery based activities are aligned to the concepts of strengths based practice and it is indeed very much linked to the social work values of practice. This concept of recovery has emerged in mental health as a response to the dominant view that practitioners are seen as the experts and clients are seen to be passive receipts of treatment. This prevailing discourse, however has been challenged by the notion of "self agency" (Chiu, Davidson, Lo, Yiu, \& Ho, 2013,p.414) and the resilience of each individual. In this paper, our main focus is more about assessment and how strengths based assessment can be beneficial and effective in the recovery process.

\section{Strengths Based Practice?}

Strengths based practice refers to the identification of strengths within an individual, family, or community. These strengths are then employed to aid in promoting self-fulfilment and healing in a client. This practice 
demonstrates a deliberate shift away from language and practice based on a client's deficits or pathology, a widespread approach that has dominated many fields within social science for some time. Focussing on strengths is not, however, a new idea and can be found in the writings and practice of many of our past great philosophical leaders and individual practitioners (Francis \& Pulla, 2014). The use of strengths based practice in the social work context has been extensively researched and promoted over the last thirty years and is becoming formalised as a method of best practice across many disciplines and countries, with global cooperation adding depth to ongoing discussion and practice guidelines. Strengths-based practice in social work has been an area of practice for quite some time now. The application of this approach has been found in many areas, contexts, and countries. The idea of strengths based practice has found a great place in the area of mental health and among many mental health social workers. While there has been a critique of the use of this concept, there has been a marked interest among social workers to embrace this philosophical shift in their own areas of practice. A recently edited book on 'Advancing Social Work in Mental Health through Strengths Based Practice' by Francis, Pulla, Clark, Mariscal and Ilango (2014) is a true demonstration of the celebration of the concept used across the world. In this paper, the strengths perspective will be discussed with an emphasis on the application of this approach in the mental health field. In recent years, the Strengths Model has been applied to engage with people with a mental illness. "The strength model of case management offers both a theory and a set of tools and methods designed to help people with psychiatric disabilities to recover and transform their lives, by attaining the goals they set for themselves as the needed personal and environmental resources are identified, secured, and sustained. It is a practice theory that contains structural, supervision, and practice elements developed by Charles Rapp and Richard Goscha at the University of Kansas" (Mariscal, 2014, p.125). Their model of strengths based practice is infused with the recovery vision, as "every contact with a person can be an opportunity for building hope, increasing confidence, and taking steps to create a better life" (Rapp \& Goscha, 2011, p. 36).

The strengths perspective represents a paradigmatic shift in social work practice that focuses on the strengths, assets, and resources that people and communities have to assist people in achieving their goals and realising their hopes and dreams. This perspective emerged in the early 1980s at the University of Kansas under the leadership of remarkable scholars such as Dennis Saleebey, Charles Rapp, and Ann Weick (Mariscal, 2014). They were able to articulate a set of notions that held promise for multiple client populations, in multiple settings and systems, and using a broader range of methods. A strengths based practice encompasses any practice that focuses on facilitating the discovery, exploration, mobilisation, development, and use of the strengths, assets, and resources that people and communities have in order to achieve their goals and realise their dreams and aspirations. It is very important to recognise the inherent qualities of people and communities and to appreciate the diversity of strengths that bring possibilities to practice. Strengths based practitioners therefore "bring possibilities, promises and hopes" (Francis \& Pulla, 2014, p. 27).

Strengths-based practice is about helping people realize they have the power to affect their own lives and exert some control in carving out their future. This does not mean that people will not have challenges, struggles, or face difficult barriers in achieving the life they want. This is part of the human condition we all face. The identification and use of strengths is helping people change narratives about themselves and their world so they can navigate the difficulties of life like everyone else (Rapp \& Goscha, 2014, p. 35).

Strengths-based practice is gaining importance in contemporary social work practice in India. In recent years, there have been some publications and research papers that reflected this change in the practice context in India. (Ponnuswami, Francis, \& Udaikumar, 2012; Francis, 2012; Pulla, 2012; Pulla et.al, 2012, Shekhar, Ponnuswami, \& Francis, 2014).

\section{What is Recovery?}

Recovery has become the guiding principle of the mental health system, resulting in advocacy for care and services that would facilitate ongoing changes in the lives of people. Recent literature on recovery describes it as deeply personal and unique to each individual and that recovery unfolds within a social and interpersonal context (Topor, Borg, DI Girolamo, \& Davidson, 2011). However, most of the literature describes recovery as "individuals taking control of their lives" (Beers, 1981; Deegan, 1996; Leete, 1989 as cited in Topor et al., 2011). There is no single uniform definition of recovery as the individual journey itself is unique and personal. But one of the definitions that the practitioners, researches, and consumers most often refer to is the one offered by Anthony (1993) where he identifies recovery as

... a deeply personal, unique process of changing one's attitudes, values, feelings, goals, skills and/or roles. It is a way of living a satisfying, hopeful, and contributing life even with limitations caused by the illness. Recovery involves the development of new meaning and purpose in one's life as one grows beyond the catastrophic effects of mental illness (p. 13).

Noiseux, Tribble, Leclerc, Corin, Morissette et al. (2009), in their recent work discuss recovery as

Recovery does not mean a cure, but rather an experience of adaptation to symptoms, wellbeing and a redefinition of personal identity to someone who was diagnosed with schizophrenia, states that recovery is an attitude towards various possibilities, an active stand and a non-linear 
process during which a person must find ways to face daily challenges. A person may thus not only try and fail, but may also try again in order to attain personal and professional goals. A relapse is therefore in no way an impediment to the process that characterizes recovery, but represents a move on to another stage (p. 4).

This definition emphasises the individual aspect of recovery and this has also been reflected in the various documents and polices of governments and organisations, acknowledging the importance of the "lived experience of the consumer " as a meeting point for both the practitioner and service users. Similarly in New Zealand, O'Hagan's definition from New Zealand's Blueprint (Mental Health Commission, 1998) is a simple one to follow. "Recovery is living well in the presence or absence of one's mental illness" (p. 113). Hyde, Bowles, and Pawar (2014) have asked whether recovery and biomedical models are complimentary models (p. 9). The view suggested by them indicates that they can be seen a complimentary.

recovery movement is providing the "other half" of the story, traditionally overlooked by the biomedical model. If placed together in a complimentary relationship where in the epistemic justice is addressed and lived experience is acknowledged and respected, these two approaches provide a formidable opportunity to create a responsive and effective mental health service .(p. 10).

Here, epistemic injustice is seen as downplaying the lived experience of the clients (Bell, 2014). Recovery principles ask us to listen to our clients, strengths based practice approaches direct us to engage with clients non-judgementally and encourage practitioners to engage in establishing therapeutic relationships with clients. It is in this environment of compassion, complimentary relationship, and engagement that "recovery" flourishes. This leads us to reflect on a question that is very relevant at this juncture.

\section{How Can I Become a Recovery Oriented Practitioner?}

Social work interventions range from primarily person-focused psychosocial processes to involvement in social policy, planning and development. These include counselling, clinical social work, group work, social pedagogical work, and family treatment and therapy as well as efforts to help people obtain services and resources in the community. Interventions also include agency administration, community organisation and engaging in social and political action to impact social policy and economic development. The holistic focus of social work is universal, but the priorities of social work practice will vary from country to country and from time to time depending on cultural, historical, and socio-economic conditions. According to international federation of social work (IFSW), Social work addresses the barriers, inequities and injustices that exist in society. It responds to crises and emergencies as well as to everyday personal and social problems. Social work utilises a variety of skills, techniques, and activities consistent with its holistic focus on persons and their environments.

Social work is a practice-based profession and an academic discipline that promotes social change and development, social cohesion, and the empowerment and liberation of people. Principles of social justice, human rights, collective responsibility and respect for diversities are central to social work. Underpinned by theories of social work, social sciences, humanities and indigenous knowledge, social work engages people and structures to address life challenges and enhance wellbeing (2014, http://ifsw.org/get-involved/global-d efinition-of-social-work/).

The proposal that mental health workers should explicitly train to become 'recovery-oriented practitioners' has been gathering pace for over a decade (O’Hagan, 2001; National Institute for Mental Health in England, 2004a). "A recovery-oriented practitioner is simply a practitioner who is able to effectively support people in their recovery" (Boardman \& Roberts, 2014, p. 37). Recovery-oriented practice emphasises the importance of shifting from primarily a clinical focus on people's symptoms and disabilities towards recognising and building on peoples' strengths and positive attributes (McCormack, 2007). In order to establish a therapeutic relationship with the clients, the practitioners need to establish trust, or rather gain trust, as gaining trust opens doors to the recovery process. This happens when practitioners explain things to the clients. Here, the recovery process begins and the consumer takes ownership of the process. This shift from practitioners to client is seen positive as it show respect and faith in the consumer's ability to recover and is based on strengths based assessment. The power is given back to the consumer in this process where they are able to understand and organise their Individual Care Plan, or Recovery \& Relapse Prevention Plan, which again gives the consumer ownership of their recovery process. The practitioner is passive here, but is still very keen to support this journey by helping clients with problem solving skills, and above all offer them the "driver's seat" in owning their recovery process, helping them achieve their individual goals but most of all "hope". Practitioner and clients together dare to dream of possibilities, explore the existing resources, begin the journey of change and discover the stories of success.

\section{Strengths Assessment - A Recovery-oriented Approach Versus Problem Assessment}

The following table describes the assessments and indicates the focus of the assessment. This table illustrates the need to focus more on the separation of problem and the person. When the assessment focus is on diagnosing, the 
individual story can be lost and the voice of the consumer will become insignificant. But the focus of strengths-based assessment is more about strengths rather than deficits. This does not mean that "problems are discounted "but through the process of assessment the strengths are identified to address these issues. At the end of table 1., I have provided 2 case studies and I would ask the readers to work through some of these issues based on the focus on the assessments mentioned here. What would be your focus? How will you be able to support them in their recovery? What is your recovery frame work? I have only provided the reader with case scenarios and not any responses as there may be different approaches to practice based on the context where each of the readers is practicing. Hence it is intended that each of you will be able to come up with a set of answers. But ask yourself these questions. Who is my client? Is the client benefiting out of this work? What is my approach to practice? How can I meaningfully engage with the clients?

\section{Case study 1}

(Note: Names of the clients, and places mentioned in these case studies have been changed to protect the identity of the clients. Only part of the story is mentioned here to discuss the strengths based assessments and to engage with the readers to generate critical reflections on practice in social work. Now, imagine that you are asked to work with one of the clients below. Please look at the issues that these cases studies present and see how strengths based approach can be adopted in practice. In a university/college setting, you could use your study groups to discuss this further.)

\section{Mr. Brown's threatening Calls}

The local mental health team received a referral from a General practitioner's clinic (GP Clinic) stating that one of the clients phoned today and threatened to harm the staff and doctors in the surgery. Now, you are requested to follow up with this case. How will you assess? What would be your focus? Is there a recovery frame work? Is recovery possible?

Table 1. The Assessment: Problem vs Strengths

\begin{tabular}{|c|c|c|}
\hline Key idea & Problem assessment & Strengths assessment \\
\hline Problem & $\begin{array}{l}\text { Diagnosis of the problem. } \\
\text { What is the cause? Why it is a problem? }\end{array}$ & $\begin{array}{l}\text { Defines what the person wants, desires, aspires to, dreams of; the } \\
\text { person's talents, skills, and knowledge. }\end{array}$ \\
\hline Nature & $\begin{array}{l}\text { Searches for the nature of client's problem from the } \\
\text { professional perspective. }\end{array}$ & $\begin{array}{l}\text { Gathers information from the standpoint of the consumer's view } \\
\text { of their situation. The lived experience is acknowledged and } \\
\text { appreciated. }\end{array}$ \\
\hline Style/relationship & $\begin{array}{c}\text { Problem assessment is usually an interrogative } \\
\text { interview. }\end{array}$ & $\begin{array}{l}\text { Strengths assessment is conversational and purposeful.it is based } \\
\text { on a therapeutic alliance between the client and practitioner. }\end{array}$ \\
\hline Focus & Focus on diagnosis and level of functioning. & $\begin{array}{l}\text { Focus on the here and now, and the individual's personal toolkit. } \\
\text { What has helped you to move on? }\end{array}$ \\
\hline Perception & $\begin{array}{l}\text { Views the client as lacking insight regarding behaviour } \\
\text { or in denial regarding scope of problem/illness }\end{array}$ & $\begin{array}{l}\text { Views persons as unique human beings who will determine their } \\
\text { wants within self and environment. }\end{array}$ \\
\hline Who is in control? & $\begin{array}{l}\text { Clients become passive recipients for interventions as } \\
\text { a result of provider's direct decision-making. Problem } \\
\text { assessment is controlled by the professional }\end{array}$ & $\begin{array}{l}\text { Clients involved in a partnership, providing encouragement, } \\
\text { coaching and validation. } \\
\text { Strengths assessment allows consumer authority and ownership } \\
\text { over their own recovery process }\end{array}$ \\
\hline Criteria & $\begin{array}{l}\text { Problem assessment places the person in diagnostic or } \\
\text { problem category and generalises the person }\end{array}$ & $\begin{array}{l}\text { Strengths assessment is specific and detailed and individualises } \\
\text { the person }\end{array}$ \\
\hline Emphasis & $\begin{array}{l}\text { Emphasises compliance and management of problems } \\
\text { and needs with formal services }\end{array}$ & $\begin{array}{l}\text { Explores the rejuvenation and creation of natural helping } \\
\text { networks seen as a solution }\end{array}$ \\
\hline $\begin{array}{l}\text { Role of the } \\
\text { practitioner }\end{array}$ & $\begin{array}{l}\text { Problem assessment - the professional dictates, "What } \\
\text { I think you need to learn/work on." }\end{array}$ & $\begin{array}{l}\text { Strengths assessment - the professional asks "What can I learn } \\
\text { from you?" How can I support you? } \\
\text { The question is do I see possibilities as a practitioner? }\end{array}$ \\
\hline
\end{tabular}

(Key ideas adopted from Rapp \& Goscha, 2011, Pulla, 2012 and Francis, 2013) 
A brief description of the client and context is as follows -

This is a case of a 64 year old single male, living in a rural town on his own at his privately owned residence for more than 15 years. He is locally known to all. However, in recent years he has started demonstrating a set of unique behavioral patterns i.e. walking in the midst of the street, often talking to himself, agitated and angry at times, picks up quarrels with the shopkeepers and the latest being the threat to kill staff. He does not have a history of violence, imprisonment or sentences. However, he has had issues with the police/law in recent times. He complains of tooth ache, body pain, diagnosed with schizo- affective disorder, and addicted to marijuana. He presents well in the afternoons when he is a bit free from his marijuana intake and speaks politely. At other times he can be seen as a threat to others and subsequently the community has been very scared of his presence recently. He drinks a lot of green tea and does not have proper meals and believes that the green tea is the only solutions to his ailments and hence does not take his prescribed medication.

\section{Some of the he issues identified are as follows-}

- Poor personal hygiene and does not maintain the house properly

- Aggressive behavior at doctors surgery

- Safety issues and risk to the community and people

- No immediate family or friends to support him

- Irrational thoughts and actions

- Conflict with the law in recent times

- Does not take medications regularly

There are many questions that arose in this situation and I would like to bring them to the attention of readers as this might help you look at the situation, not just from the view point of safety, but also from a social work perspective. What are some of the factors that could be considered in responding to similar cases in practice? What would be the focus here? How strengths - based assessment could be implemented here? Please critically reflect on the following questions:-

- Why Mr. Brown is responding to situations this way as discussed in the case study?

- Can we look at this case from a strengths perspective? What are some key issues here? How could this be explored further?

- Is there a link between his consumption of marijuana and his behavior pattern? Why has there been a big change observed recently? (Especially in the context of his prolonged use of marijuana).

- What is the cause of this irrational behaviour and poor hygiene?

- This case demonstrates a real example of deteriorating mental health; how could this be related to his past? Or life events? What steps need to be taken to support this client?
- What lessons can be drawn from science/neuroscience to meaningfully engage with this client?

\section{Case Study 2 Mrs. Green with anxiety disorder}

Mrs. Green has been referred to the local service with an anxiety disorder. A brief description is provided here:

Mrs. Green is a 30 year old female living with her husband and an 8 month old child in a rural town in a western country. In an interview, she admitted having depression for many years, but stated that it hasn't affected much of her day to day life. However, she has been on medication for several years since being diagnosed with depression as a teenager. She said "as a teenager, I had these problems, and I also used to take some drugs occasionally, but I gave it up after my marriage". Her newest problem is constant fear and worry that the world is trying to get her child, which reached to the extreme of her constantly checking the nappy of the child, fearing that germs will kill her baby. This behavioral pattern has not only caused relationship issues with her husband and friends but also limited her interactions within the wider community. She withdrew from social networks, stopped attending social activities, discontinued her studies and disconnected herself from the extended families. She doubted her ability to care for her child, had very different expectations about a mother and was very anxious about the way she could protect her child from any adversities, particularly the germs.

\section{Some of the key issues identified and questions are as follows-}

- Is there any association with her childhood experiences and her current experiences?

- How could her mothering role be challenged?

- How could we better understand her world view?

- Is there an association between her previous drug use and current mental state?

- What are the symptoms saying to us? Are there lessons to be drawn from other disciplines? How could this be done?

- Are there attachment issues? How could these be explored? What questions can be asked?

- $\quad$ Could this be discussed with her husband? How would this be perceived then?

- What would be my approach/language and process?

Based on these two case studies, I now invite the attention of the readers to look at the issues carefully and reflect whether we could employ strengths based approach to assessment, and what would you see as recovery in this context. What are some of the questions that you would ask the clients? How would you ask? What will be the reframing words and how will you support the clients in their recovery?

\section{Some Tips for Practice}

To help the client rediscover his/her strengths and abilities, social workers are encouraged to convey a positive and 
optimistic attitude and use an approach based on partnership and collaboration. This will increase the resources available to identify creative options and "...solutions developed collaboratively are more likely to be useful to the service user than those imposed by others..." (Healy, 2005, p. 161). As a practice perspective (Sheafor, et al. 1996, p. 51) the strengths approach takes a different look at the client, his problems and his environment, and it requires a different approach from social workers. This is also echoed when Miley, O'melia and Dubois (2004, p. 81) stress that practitioners need to re-examine their orientation to practice, their views of client systems and the issues clients represent if the strength perspective is to be applied. According to them $(2004$, p. 81$)$, the practice of the strengths perspective will prompt social workers to examine three transitions from problems to challenges, from pathology to strengths and from a preoccupation with the past to an orientation to the future. We can simply define resilience as the ability to successfully adapt in the face of adversity. People can manifest this inherent quality in several ways that practitioners need to be aware of when working with clients. So as we engage in the work, this attitude and philosophical shift in our practice needs to be displayed so that our focus will remain on the possibilities and human capacities and not on the challenges and problems. However this requires the "practitioner to believe in his or her clients' resilience and who mirrors this belief back to the client" (Bernard \& Truebridge, 2013, p. 207). Bernard further states that

Practitioners with "resilience prospective" believe that all people have a resilient nature. Moving to a resiliency approach requires a personal transformation of vision ... the lens through which we see our world. To make systemic changes .... Depends on changing hearts and minds (1993).

In their recent article Rapp and Sullivan (2014) state that "[ $t]$ he importance of recognizing and exploiting strengths in the natural environment is vitally important to social work, and is one clear area that distinguishes this discipline from others in the helping professions" (2014, p. 137). A social worker's role in assisting the client is underpinned by several practice principles. These include: adopting optimism, a language of hope and seeing the environment as full of resources; according deep respect for the family's frame of reference; demystifying the professional role and elevating The client to the level of 'expert' in a collaborative alliance; highlighting the family's strengths, resources and capabilities in the face of 'challenges' to facilitate their discovery of the power within themselves; avoiding 'victim mindsets' and engaging clients' motivation for change through strengths; being flexible and open to negotiation as the client priorities change; and fostering links to communities and contexts where clients' "... strengths can flourish" (De Jong \& Miller, 1995, p. 730; Saleebey, 2009). Therefore, it will be appropriate for the practitioner to consider before commencing any work with his/her clients.
1. Have a strong belief in the power of people that they can recover and demonstrate a commitment to service.

2. Establish a therapeutic partnership with the client, family, and other networks.

3. Develop open communication, and patient listening with the clients and families.

4. Have an understanding that recovery is unique for each person and people may be at various stages of recovery. There is no "one size fit for all" approach in recovery.

5. Recovery is based on the foundation of hope and it is also about nurturing relationships.

6. Encourage and celebrate the achievements of your "clients" even if it is a small step towards recovery (Francis, 2012, 2013).

\section{Conclusions}

The strengths perspective is not about discounting problems and ignoring the issues. It is not just about positive thinking. While there are still debates about the application of these concepts, many social work practitioners who have come into contact with me over the years are of the opinion that strengths based practice models have really worked for them. However, it must be noted that the strengths perspective does not consist of "only a positive reframing" of a problem, "being nice", or compiling a list of strengths (Early \& GlenMaye, 2000; Saleebey, 1996). It refers to a "consistent focus on identifying client strengths and resources and mobilizing resources that directly or indirectly improve the situation" (Early \& GlenMaye, 2000, p. 123).

Recovery does not just happen in a vacuum. It needs an environment of support, cooperation, and partnership that can foster hope. "Because hope is the foundation of recovery" (Gehart, 2011 p. 444, Onken, 2012). "The road to recovery starts only when we acknowledge and accept our mental illness and the toll it has taken in our life. After such an acknowledgment we can start taking steps to improve our life and work towards the sort of future we want or imagine" (Middlemiss, 2012). This realisation is a difficult thing in the beginning as people with mental illness may be socially isolated and may not have the luxury of human connections. It is at this juncture we need people with a sense of head, heart, and minds to walk in to the lives of people who demonstrate a sense of commitment and compassion. This acknowledgement is nourished again in an environment of positive thinking, collaboration, compassion, and by recognising the strengths of the individual. This emphasis on strengths is used as a foundation for the recovery partnership (between a service provider and a service recipient) and is also central in mapping the recovery and facilitating the recovery process (Gehart, 2011). By engaging with clients with a sense of hope and a belief that people can change, social workers can work with the client to identify a sense of purpose for their life, create a sense of belonging, and 
develop a sense of hope. Working from the strengths based approach will ensure that the client is supported to move towards recovery. Clearly, the strengths perspective involves an empowering, healing, and completeness process that demands far more than acquiring new techniques, vocabulary, or protocols. This perspective requires a deep transformation of the practitioner's beliefs and worldview; what we look for, and what we listen for, shift as we focus on potential, possibility, promise, skills, experience, wisdom, assets, knowledge, and the smallest sparkle of hope. As Saleebey (2001) asserts, to embrace strengths based approach involves "changing one's heart and mind- a personal paradigm shift" (p. 13). The question is - Are we ready to embrace such a shift in practice?

\section{REFERENCES}

Australian Bureau of Statistics (ABS). (2007). National survey of mental health and wellbeing: Summary of results, 2007. Canberra, ACT: ABS.

Australian Health Ministers, (2003). National Mental Health Plan 2003-2008, Retrieved 12 October 2014 from http://www.health.gov.au

Anthony, W. (1993). Recovery from Mental Illness: The Guiding Vision of the Mental Health Services in the 1990's. Psychosocial Rehabilitation Journal, 16(4), 11-23.

Bernard, B., \& Truebridge, S. (2013). A shift in thinking in Dennis Saleebey (6th edition) the strengths perspective in social work practice, Pearson Education, Inc. USA.

Bell, K. (2014). Exploring epistemic injustice through feminist social work research. doi:10.1177/0886109913516457.

Bland, R., \& Tullgren, A. (2014). Recovery theory and practice. In A. Francis. (Ed.), Social work practice in mental health. Delhi: Sage.

Chiu, M. Y., Davidson, L., Lo, W. T., Yiu, M. G., \& Ho, W. W. (2013). Modeling self-agency among people with schizophrenia: Empirical evidence for consumer-based recovery. Psychopathology, 46, 413-420.

De Jong, P., \& Miller, S. (1995). How to interview for client strengths. Social Work, 40(6), 729 -736.

Early, T., \& Glenmaye, L. (2000). Valuing families: Social work practice with families from a strengths perspective. Social Work, 45(2), 118-130.

Francis, A. (2012). 'Journey towards recovery in mental health'. In V. Pulla, L. Chenoweth, A. Francis, \& S. Bakaj (Eds.), Papers in strengths based practice (pp. 19-33). New Delhi: Allied Publishers.

Francis, A. (2013). 'I get up, because I know I can go to my group today': Examining the healing power of relationship in support. International Journal of Social Work and Human Services Practice, 1(1), 54-63.

[18] Francis A, Pulla, V, Clark, M, Mariscal SE \& Ponnuswami, I (Eds.)(2014) Advancing social work in mental health through strengths based practice. Australia: Primrose Publications.
Gehart, D. (2011). The mental health recovery movement and family therapy Part one: Consumer-led reform of services to persons diagnosed with severe mental illness. Journal of Marital and Family Therapy. doi: 10.1111/j.1752-0606.2011.0022 9.x

Gehart, D. (2011). The mental health recovery movement and family therapy Part two: A collaborative approach for supporting mental health recovery. Journal of Marital and Family Therapy, 38. doi: $10.1111 / \mathrm{j} .1752-0606.2011 .00229 . x$

IFSW. (2014.) Proposed global definition of the social work profession, retrieved from http://ifsw.org/get-involved/global-defin ition-of-social-work/

Healy, K. (2005). Social work theories in context: Creating frameworks for practice. New York: Palgrave MacMillan.

Hyde, B., Bowles, W., \& Pawar, M. (2014) Challenges of recovery oriented

Practice in inpatient mental health settings - the potential for social work leadership, Asia Pacific Journal of Social Work and Development, 24:1-2, 5-16, DOI: 10.1080/02185385.2014.885205

Mariscal, S. E. (2014). The strengths perspective and the strengths model of case management: Enhancing the recovery of people with psychiatric disabilities. In A. Francis, V. Pulla, M. Clark, S. Mariscal \& I. Ponnuswami (Eds.), Advancing social work in mental health through strengths based practice (pp. 73-87). Australia: Primrose Publications.

McCormack, J (2007) Recovery and Strengths Based Practice (SRN Discussion Paper Series: Report No 6). Scottish Recovery Network.

Middlemiss, J. (2012). Secret squirrel business: A guide to mental health recovery. West Perth, Australia: Ruah Community Services.

Miley, K. K., O'melia, M., \& Dubois, B. (2004). Generalist social work practice: An empowering approach. Boston: Allyn and Bacon.

National Institute for Mental Health in England (2004a) The Ten Essential Shared Capabilities: A Framework for the Whole of the Mental Health Workforce. Department of Health.

Noiseux, S., Tribble, D., Leclerc, C., Corin, R. N., Morissette, E., \& Lambert, R. (2009). Developing a model of recovery in mental health. doi: 10.1186/1472-6963-9-73

O’Hagan M (2001) Recovery Competencies for New Zealand Mental Health Workers. Mental Health Commission.

O'Hagan, M. (2004). Recovery in New Zealand: Lessons for Australia? Australian e-Journal NSW CAG \& MHCC - Literature Review on Recovery for the Advancement of Mental Health, 3 (1), $1-3$.

Onken, S. (2012). Exploring relationships in mental health. Key note presentation at 2012 ASPAC conference, Perth, Australia, June 11-13, retrieved from https://www.rfwa.org.a $\mathrm{u} /$

Ponnuswami, I., Francis, A., \& Udhayakumar, P. (2012). Strengths-based approach to social work practice with older persons. In A. Pulla, L. Chenoweth, A. Francis, \& S. BaKaj (Eds.), Papers in strengths-based practice (150-161). New Delhi, India: Allied Publishers.

Pulla, V. (2012). What are strengths based practice all about? In Pulla, V., Chenoweth, L., Francis, A., \& S. Bakaj (Eds.), Papers in 
strengths based practice. New Delhi: Allied Publishers.

Pulla, V., \& Francis, A. (2013). A strengths approach to mental health. In A. Francis (Ed.), Social work practice in mental health. Sage Publications.

Pulla, V., \& Francis, A. (2014). Introduction In A. Francis, V. Pulla, M. Clark, S. Mariscal \& I. Ponnuswami (Eds.), Advancing social work in mental health through strengths based practice (pp. 27-30). Australia: Primrose Publications.

Pulla, V., Chenoweth, L., Francis, A., \& Bakaj, S. (Eds.). (2012). Papers in strengths based practice. New Delhi: Allied Publishers.

Roberts, G., and Boardman, J. (2014) becoming a recovery-oriented practitioner, Advances in Psychiatric Treatment (2014) 20: 37-47 doi: 10.1192/apt.bp.112.010652

Rapp, C. A., \& Goscha, R. J. (2011). The strengths model: A recovery-oriented approach to mental health services. Oxford University Press.

Rapp, C., \& Goscha, R. (2014). Three decades of strengths: Reflections of the past and challenges of the future. In A. Francis, V.
Pulla, M. Clark, S. Mariscal \& I. Ponnuswami (Eds.), Advancing Social work in mental health through strengths based practice (pp. 31-38). Australia: Primrose Publications.

Saleebey, D. (Ed.). (2001). The strengths perspective in social work practice (3rd ed.). Boston: Allyn and Bacon.

Saleebey, D. (Ed.). (2009). The strengths perspective in social work practice (5th ed.). Boston: Allyn \& Bacon.

Shekhar, R., Ponnuswami, I., \& Francis, A. (2014). Efficacy of strengths-based practice in engaging with children with behavioural problems: A case study from India. In A. Francis, V. Pulla, M. Clark, S. Mariscal \& I. Ponnuswami (Eds.), Advancing Social work in mental health through strengths based practice. Australia: Primrose Publications.

Topor, A., Borg, M., DI Girolamo, S., \& Davidson, L. (2011). Not just an individual journey, social aspect of recovery. International Journal of Social Psychiatry, 57(1), 90-99. doi: $10.1177 / 0020764010345062$ 